\title{
60th Birthday of Professor Colin F. Poole
}

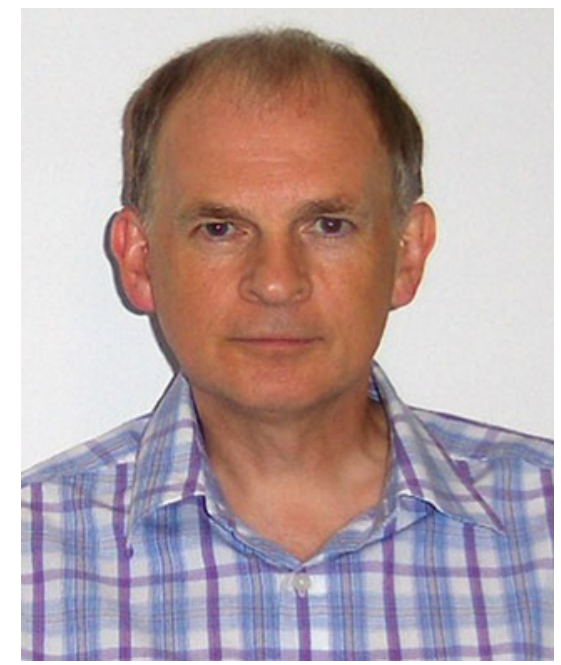

Colin Frank Poole was born in 1950 in Huyton near Liverpool in the UK. He trained first as a chemist at the University of Leeds, leading to a B.Sc. which he followed with an M.Sc. in analytical chemistry at the University of Bristol. Colin then went to join the research group of Prof. E. David Morgan at the University of Keele where he performed research into the analysis of insect hormones that was to lead to his Ph.D. in 1975. Periods of postdoctoral work at the University of Aston, then the University of Ghent were followed by his migration to the USA where he initially worked with Al Zlatkis at the University of Houston before settling in the Department of Chemistry at Wayne State University in Detroit where, with a brief interlude at Imperial College (London) between 1995 and 1996, he has been ever since.
Over all that time Colin has been a prolific researcher in a range of separation techniques spanning $\mathrm{LC}, \mathrm{GC}$, TLC, SFC, derivatising reagents, sample preparation, computer aided method development and quantitative structure-property relationships, with many hundreds of research papers and reviews to his name (not for nothing has he been termed a "polychromatographer"'). As well as his prodigious research output he has been very active editor (J. Chromatography A, J. Planar Chromatography, several encyclopedias), editorial board member, including the board of Chromatographia, teacher (as well as training numerous postgraduate students he has also run many short courses) and writer of text books. Of particular note are the immensely popular textbooks "Contemporary Practice of Chromatography" (with Sheila Schuette in 1984) and "Chromatography Today", co-written with his wife Salwa, and published in 1991. I know that these two volumes are popular, based on the number of times I have had to repurchase them after they have mysteriously vanished from my shelves never to be seen again. His work has led to honours such as the M. S. Twsett Chromatography Medal of the International Symposium on Advances in Chromatography, the 1991 Jubilee Medal from the Chromatographic Society, and the award of a D.Sc. from the University of Leeds in 1997.
My connection with Colin dates from the time that, as he left David Morgan's group at Keele I joined it to carry on the research on ecdysteroids in the desert locust for which he had been instrumental in developing the analytical methods required (GC with electron capture detection). Indeed my first meeting with him was on platform 3 of Stafford railway station where he attempted to diagnose the problems we were having silylating these hormones based on about 20 feet of chromatograms on rolls of chart paper (to this day I'm not sure what the other passengers thought we were doing). Our paths have crossed many times since over the intervening 35 years and my appreciation of him as a deeply knowledgeable chromatographer has grown with every meeting, as has my appreciation of his (very) dry, and very British, sense of humour. Many of us have had cause to be grateful to him for his expertise and energy, and we all hope that, after enjoying his birthday, he will get straight back to doing what he does so well, separations science.

Happy birthday Colin!

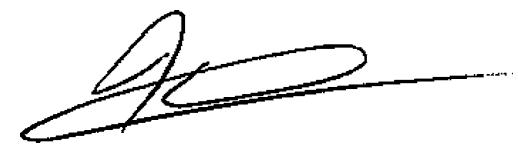

Ian Wilson 